\title{
Optimization of Gas Metal Arc Welding Process Parameters Using Standard Deviation (SDV) and Multi-Objective Optimization on the Basis of Ratio Analysis (M00RA)
}

\author{
Joseph Achebo ${ }^{*}$, William Ejenavi Odinikuku \\ ${ }^{1}$ Department of Production Engineering, University of Benin, Benin City, Nigeria \\ ${ }^{2}$ Department of Mechanical Engineering, Petroleum Training Institute, Effurun, Nigeria \\ Email: "josephachebo@yahoo.co.uk
}

Received 1 June 2015; accepted 15 June 2015; published 18 June 2015

Copyright (C) 2015 by authors and Scientific Research Publishing Inc.

This work is licensed under the Creative Commons Attribution International License (CC BY). http://creativecommons.org/licenses/by/4.0/

\section{(c) (i) Open Access}

\begin{abstract}
Welding technology is very vital for the industrial development and technological advancement of any country. In this regard achieving good quality machine manufactured products cannot be over emphasized. Since welding is a very reliable method of joining metals together permanently, several methodologies have been adopted to improve the quality of weldments, such as the neural network, fuzzy logic, surface response methodology, full factorial method, and so on. In this case, the multi-objective optimization on the basis of ratio analysis (MOORA) is applied. MOORA is used to solve multi-criteria (objective) optimization problem in welding. MOORA in combination with standard deviation (SDV) was used for the optimization process. SDV was used to determine the weights that were used for normalizing the responses obtained from the mechanical test results. From applying the SDV-MOORA method, it was found that welding current of 350 A, welding voltage of $22 \mathrm{~V}$, an electrode diameter of $3.2 \mathrm{~mm}$ and welding speed of $100 \mathrm{~mm} / \mathrm{s}$ produced the weldment with the best mechanical properties. The mechanical properties compare very well with those obtained from other literature. It is, therefore, concluded that the SDV-MOORA method has successfully optimized the welding process parameters used in this study.
\end{abstract}

\section{Keywords}

SDV, MO0RA, Welding Process, Bead Geometry, Mechanical Property

\footnotetext{
${ }^{*}$ Corresponding author.
}

How to cite this paper: Achebo, J. and Odinikuku, W.E. (2015) Optimization of Gas Metal Arc Welding Process Parameters Using Standard Deviation (SDV) and Multi-Objective Optimization on the Basis of Ratio Analysis (MOORA). Journal of Minerals and Materials Characterization and Engineering, 3, 298-308. http://dx.doi.org/10.4236/jmmce.2015.34032 


\section{Introduction}

The failure of structural materials especially steel is of great concern globally. In Nigeria, steel pipes used for the transportation of water, oil, gas etc. are joined together by welding. Welding is designed to permanently join pieces of materials producing weldments which significantly enhance the rigidity, stability, reliability, and integrity of structural materials. If the quality of the weldment is poor, the weldment will fail either by breaking off due to its brittle nature or by corrosion. It has been proven by several researchers that the choice of welding input process parameters can alter the quality of the weldment. Therefore, optimizing these process parameters to obtain the best weld quality and multi-response properties cannot be over emphasized. The choice of the appropriate optimization tool is an ongoing research process. Researchers are using different methods to obtain the most economic input process parameters. Today, there is no known particular optimization method used for optimizing these input process parameters. Instead, several optimization methods are used and the one that has produced the most acceptable results is selected. MOORA is one of such techniques that have not been fully utilized in optimizing welding input process parameters and multi-response properties.

The international engineering and welding community is keenly interested in investing in research and development geared towards finding optimized methods for obtaining weldments of acceptable quality. Several expert methods such as artificial neural network, fuzzy logic, finite element, genetic algorithm etc. have been applied for optimizing process parameters, since it has been found that applying the most appropriate process parameters has a huge impact on the eventual quality of each weldment. It has become imperative that new methods should be explored for the purpose of obtaining better weldments to meet even more specific engineering requirements.

In this study, the Multi-Objective Optimization on the basis of Ratio Analysis (MOORA) is used to optimize the process parameters. Görener et al. [1] were of the opinion that the MOORA method was first used by Brauers [2]. The MOORA method is a relatively new multi-criteria decision-making method which is based on the ratio system as well as dimemsionless measurement [3] [4].

Gadakh et al. [5] were of the opinion that multi-objective optimization (or programming), also known as multi criteria or multi-attribute optimization, was the process of simultaneously optimizing two or more conflicting attributes (objectives) subject to certain constraints. Hwang and Yoon [6] said that multi-criteria decision-making was applied to decisions among available classified alternatives by multiple attributes. Mandal and Sarkar [7] wrote that MOORA was the process of simultaneously optimizing two or more conflicting attributes (objectives) subject to certain constraints.

Stanujkic et al. [8] were of the opinion that multiple-criteria decision-making (MCDM) could be generally described as the process of selecting one from a set of available alternatives, or ranking alternatives, based on a set of criteria, which usually had a different significance. The multi-objective optimization by ratio analysis (MOORA) which was a part of MCDM was first introduced by Brauers and Zavadskas [9].

Some researchers have used MOORA for solving product or system optimization problems. Chakraborty [10] applied the MOORA method for decision-making in a manufacturing environment. Karande and Chakraborty [11] applied the MOORA method for the selection of materials. Chaturvedi and Sharma [12] optimized CNC wire cut EDM for OHNS steel using MOORA methodology. Görener et al. [1] applied the MOORA method for selecting where a bank should be located. Gadakh et al. [5] optimized welding process parameters using the MOORA method.

Brauers and Zavadskas [13] expanded the scope of MOORA to be known as MULTI-MOORA. Ozcelik et al. [14] in their paper wrote that Brauers and Zavadskas [13] developed the equation for the full multiplicative form of MOORA known as MULTI-MOORA method. Farzamnia and Babolghani [15] applied the group decision making process for material supplier selection in a supply chain using MULTI-MOORA technique under fuzzy environment.

In this study, the SDV-MOORA method was used to optimize the welding process parameters used for gas metal arc welding of mild steel plates. SDV was the standard deviation method used for determining the weight attached to each mechanical property. The results obtained from the optimized process parameters would be compared with those obtained using other optimization methods.

\section{Materials and Methods}

\subsection{Materials}

Five large weld deposits were made for each application of the sixteen process parameters on $4 \mathrm{~mm}$ mild steel 
plates. Each of these weld deposits are sectioned into three parts. One part was used to determine the Bead geometry (see Figure 1), the other part was used to conduct the Charpy V-Notch (CVN) Impact test. The CVN specimen is shown in Figure 2, while the remaining part was machined into the tensile specimen (see Figure 3) for conducting the tensile test.

Five tensile specimens are prepared using a CNC Lathe machine. Tensile tests are carried out in $100 \mathrm{kN}$ computer controlled Universal Testing Machine as used by Prasad et al. [16]. The specimens were loaded at a rate of $1.8 \mathrm{kN} / \mathrm{min}$ as per ASTM specifications, so that these tensile specimens can undergo the deformation process. From the stress strain curve obtained, the ultimate tensile strength (UTS) of the weld joints is evaluated and the average of the five test results was recorded.

\subsection{Method}

The method adopted by El-Santawy and Ahmed [18] was used in this study. The methodology is expressed as contained herein under:

\subsubsection{Weight Allocation via Standard Deviation}

Standard deviation is applied to this study for unbiased allocation of weights. The importance of weights in solving Multi-Criteria Decision Making (MCDM) problems cannot be over emphasized. To determine the standard deviation, the range standardization was done using Equation (1) to transform different scales and units among various criteria into common measurable units in order to compute their weights.

$$
X_{i j}^{\prime}=\frac{X_{i j}-\min _{1<j<n} X_{i j}}{\max _{1<j<n} X_{i j}-\min _{1<j<n} X_{i j}}
$$

where $\max X_{i j}, \min X_{i j}$ are the maximum and minimum values of the criterion $(j)$ respectively. The Standard deviation $(S D V)$ is calculated for every criterion using Equation (2)

$$
S D V_{j}=\sqrt{\frac{1}{m} \sum_{i=1}^{m}\left(X_{i j}-\overline{X_{j}^{\prime}}\right)^{2}}
$$

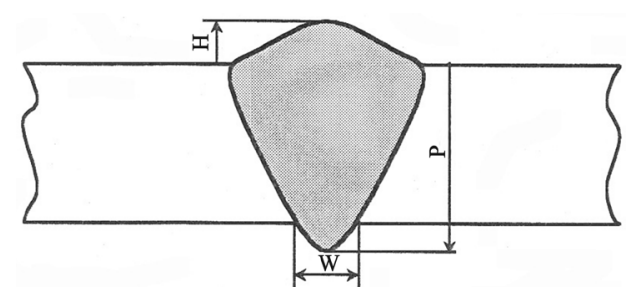

Figure 1. Bead geometry [17].

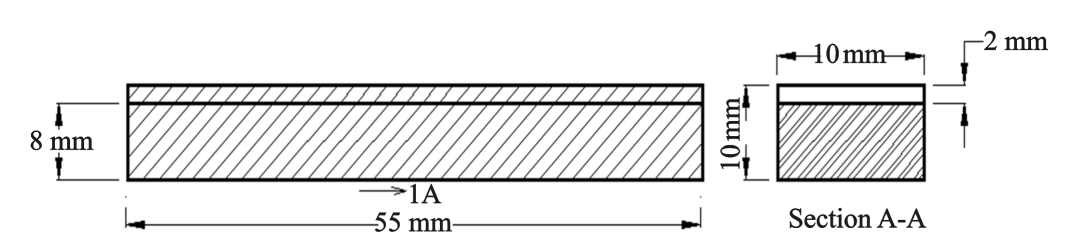

Figure 2. Schematic diagram of charpy V notch impact test specimen.
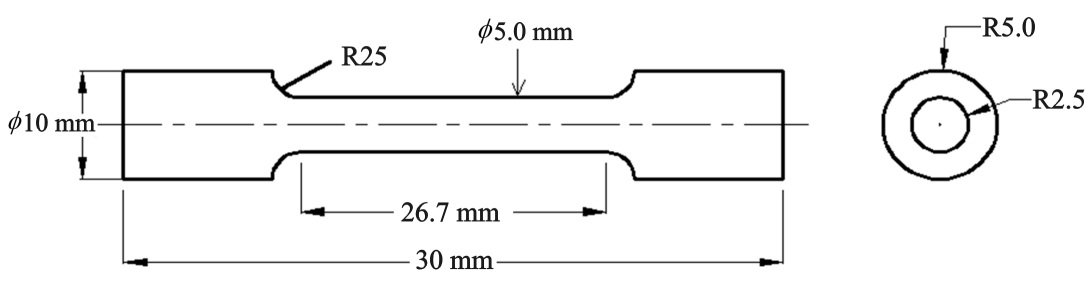

Figure 3. Schematic diagram of tensile specimen. 
where $\overline{X_{j}^{\prime}}$ is the mean of the values of the $j^{\text {th }}$ criterion after normalization and $j=1,2, \cdots, n$. After calculating for $S D V$ for all criteria, the next step is to determine the weights, $W_{j}$ of all the criteria considered.

$$
W_{j}=\frac{S D V_{J}}{\sum_{j=1}^{n} S D V_{J}}
$$

where $j=1,2, \cdots, n$.

\subsubsection{Application of MOORA}

The Multi-Objective Optimization on the basis of Ratio Analysis (MOORA) method starts with a decision matrix as expressed by Equation (4)

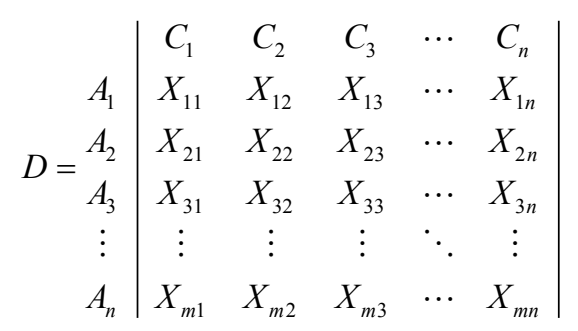

The procedure for using MOORA for ranking alternatives is described here under;

Step 1: Compute the normalized decision matrix by vector method as defined by Equation (5)

$$
X_{i j}^{\prime}=\frac{X_{i j}}{\sqrt{\sum_{i=1}^{m} X_{i j}^{2}}}
$$

where $i=1, \cdots, m ; j=1, \cdots, n$

Step 2: Calculate the composite score as expressed in Equation (6)

$$
Z_{i}=\sum_{j=1}^{b} X_{i j}^{\prime}-\sum_{j=b+1}^{n} X_{i j}^{\prime} ; \text { where } i=1, \cdots, m
$$

where $\sum^{b} X_{i j}^{\prime}$ and $\sum^{n} X_{i j}^{\prime}$ are the benefit and non benefit (cost) criteria, respectively. If there are some attributes=-more important than the others, the composite score becomes as expressed in Equation (7)

$$
Z_{i}=\sum_{j=1}^{b} W_{j} X_{i j}^{\prime}-\sum_{j=b+1}^{n} W_{j} X_{i j}^{\prime}, i=1, \cdots, m
$$

where $W_{j}$ is the weight of $j^{\text {th }}$ criterion

Step 3: Rank the alternatives in descending order.

Figure 4 shows the sequence of operations that was performed in the framework of multicriteria decision support system

\section{Results and Discussion}

\subsection{Results}

The matrix design used to prepare the layout for the welding procedure is presented in Table 1.

Table 2 shows the welding process parameters and their levels

Table 3 shows the decision matrix used for categorizing the weld mechanical properties and bead geometry

Where UTS is the Ultimate Tensile Strength, CVN is the Charpy V-Notch Impact Energy, BP is the Bead Penetration, BH is the Bead Height and BW is the Bead Width.

\subsubsection{Weight Allocation}

In this study, the weight allocation for each of the output parameters, that is, the weld mechanical properties and 
the bead geometry were determined. In determining the weight, the range of standardized decision matrix is determined using Equation (1). Table 4 shows the summary of the range of standardized decision matrix.

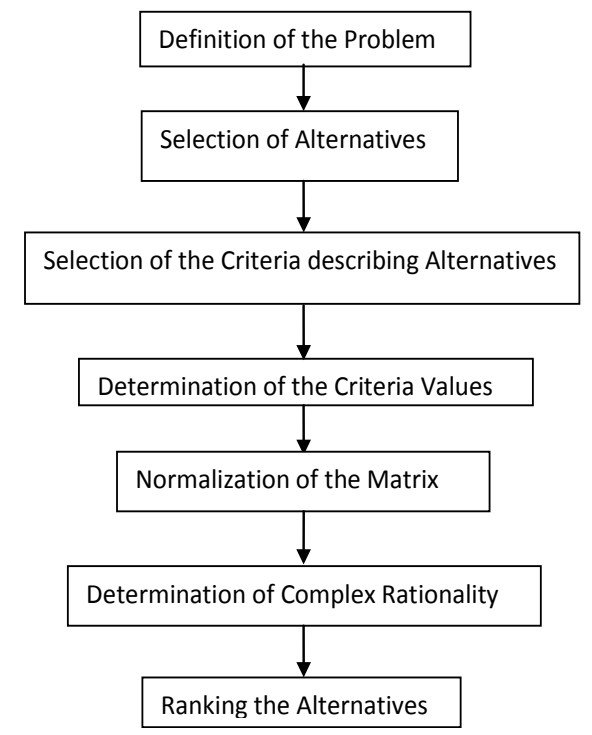

Figure 4. Sequence of operations performed in the framework of multi-criteria decision support system [19].

Table 1. Matrix design.

\begin{tabular}{ccccc}
\hline & A & B & C & D \\
0 & 1 & 2 & 3 & 4 \\
+ & + & - & - & - \\
+ & + & + & - & - \\
+ & + & + & + & + \\
+ & + & + & + & + \\
+ & - & + & + & + \\
+ & + & - & + & + \\
+ & - & + & - & - \\
+ & + & - & + & + \\
+ & + & + & - & - \\
+ & - & + & + & + \\
+ & - & - & + & + \\
+ & + & - & - & - \\
+ & - & + & - & + \\
+ & - & - & + & - \\
\hline
\end{tabular}

Table 2. Process parameters and their levels.

\begin{tabular}{cccc}
\hline Process Parameters & Unit & Low & High \\
\cline { 3 - 4 } Current & & 280 & 350 \\
Voltage & $\mathrm{A}$ & 22 & 38 \\
Electrode diameter & $\mathrm{V}$ & 1.6 & 3.2 \\
Welding speed & $\mathrm{mm}$ & 100 & 135 \\
\hline
\end{tabular}


Table 3. Decision matrix.

\begin{tabular}{cccccc}
\hline \multirow{2}{*}{$\begin{array}{c}\text { Sample } \\
\text { Number }\end{array}$} & \multicolumn{3}{c}{ Maximum } & \multicolumn{2}{c}{ Minimum } \\
\cline { 2 - 6 } 1 & UTS (MPa) & CVN $(\mathrm{J})$ & BP $(\mathrm{mm})$ & BH $(\mathrm{mm})$ & BW $(\mathrm{mm})$ \\
2 & 420 & 110 & 2.04 & 2.25 & 10.82 \\
3 & 500 & 100 & 1.12 & 2.85 & 5.14 \\
4 & 380 & 80 & 2.58 & 3.10 & 7.22 \\
5 & 320 & 90 & 1.03 & 2.51 & 11.42 \\
6 & 410 & 60 & 1.45 & 3.72 & 5.35 \\
7 & 220 & 100 & 1.05 & 2.05 & 8.83 \\
8 & 280 & 55 & 2.01 & 2.15 & 10.72 \\
9 & 510 & 115 & 3.50 & 3.88 & 4.50 \\
10 & 480 & 85 & 3.78 & 2.85 & 6.85 \\
11 & 320 & 60 & 2.15 & 2.15 & 11.20 \\
12 & 250 & 95 & 1.90 & 2.98 & 12.40 \\
13 & 310 & 83 & 2.42 & 2.06 & 9.80 \\
14 & 520 & 100 & 3.82 & 2.97 & 4.18 \\
15 & 430 & 70 & 2.25 & 3.08 & 8.32 \\
16 & 270 & 60 & 1.65 & 2.15 & 10.74 \\
& 290 & 80 & 1.88 & 2.70 & 12.88 \\
\hline
\end{tabular}

Table 4. Summary of range of standardized decision matrix.

\begin{tabular}{|c|c|c|c|c|c|}
\hline Sample No. & UTS, MPa & CVN, J & $\mathrm{BP}, \mathrm{mm}$ & $\mathrm{BH}, \mathrm{mm}$ & $\mathrm{BW}, \mathrm{mm}$ \\
\hline 1 & 0.67 & 0.92 & 0.36 & 0.11 & 0.76 \\
\hline 2 & 0.93 & 0.75 & 0.03 & 0.44 & 0.11 \\
\hline 3 & 0.53 & 0.42 & 0.56 & 0.57 & 0.35 \\
\hline 4 & 0.33 & 0.58 & 0 & 0.25 & 0.83 \\
\hline 5 & 0.63 & 0.08 & 0.15 & 0.91 & 0.13 \\
\hline 6 & 0 & 0.75 & 0.01 & 0 & 0.53 \\
\hline 7 & 0.20 & 0 & 0.35 & 0.06 & 0.75 \\
\hline 8 & 0.97 & 1 & 0.89 & 1 & 0.04 \\
\hline 9 & 0.87 & 0.50 & 0.99 & 0.44 & 0.31 \\
\hline 10 & 0.33 & 0.08 & 0.40 & 0.06 & 0.81 \\
\hline 11 & 0.10 & 0.67 & 0.31 & 0.51 & 0.95 \\
\hline 12 & 0.30 & 0.47 & 0.50 & 0.01 & 0.65 \\
\hline 13 & 1 & 0.78 & 1 & 0.50 & 0 \\
\hline 14 & 0.70 & 0.25 & 0.44 & 0.56 & 0.48 \\
\hline 15 & 0.17 & 0.08 & 0.22 & 0.06 & 0.75 \\
\hline 16 & 0.23 & 0.42 & 0.31 & 0.37 & 1 \\
\hline
\end{tabular}

The next step is to determine the standard deviation and weights using Equation (2) and Equation (3) as shown in Table 5.

\subsubsection{Application of MOORA}

In applying the MOORA method, the first step was to square each value in Table $1, X_{i j}^{2}$, this lead to the creation of Table 6.

Applying $\quad X_{i j}^{\prime}=\frac{X_{i j}}{\sqrt{\sum_{i=1}^{m} X_{i j}^{2}}}$ for each column in Table 3 and Table 6, Table 7 was created therefrom. 
Table 5. Weights assigned to criteria.

\begin{tabular}{ccc}
\hline Property & SDV $_{\mathrm{j}}$ & $\mathrm{W}_{\mathrm{j}}$ \\
\hline UTS & 0.57607 & 0.20578 \\
CVN & 0.55074 & 0.19674 \\
BP & 0.55655 & 0.19881 \\
BH & 0.53803 & 0.19220 \\
BW & 0.57800 & 0.20647 \\
\hline
\end{tabular}

Table 6. The square value of $X_{i j}$.

\begin{tabular}{cccccc}
\hline Sample No. & UTS, MPa & CVN, J & BP, mm & BH, mm & BW, mm \\
\hline 1 & 176,400 & 12,100 & 4.1616 & 5.0625 & 117.0724 \\
2 & 250,000 & 10,000 & 1.2544 & 8.1225 & 26.4196 \\
3 & 144,400 & 6400 & 6.6564 & 9.6100 & 52.1284 \\
4 & 102,400 & 8100 & 1.0609 & 6.3001 & 130.4164 \\
5 & 168,100 & 3600 & 2.1025 & 13.8384 & 28.6225 \\
6 & 48,400 & 10,000 & 1.1025 & 4.2025 & 77.9689 \\
7 & 78,400 & 3025 & 4.0401 & 4.6225 & 114.9184 \\
8 & 260,100 & 13,225 & 12.2500 & 15.0544 & 20.2500 \\
9 & 230,400 & 7225 & 14.2884 & 8.1225 & 46.9225 \\
10 & 102,400 & 3600 & 4.6225 & 4.6225 & 125.4400 \\
11 & 62,500 & 9025 & 3.6100 & 8.8804 & 153.7600 \\
12 & 96,100 & 6889 & 5.8564 & 4.2436 & 96.0400 \\
13 & 270,400 & 10,404 & 14.5924 & 8.8209 & 17.4724 \\
14 & 184,900 & 4900 & 5.0625 & 9.4864 & 69.2224 \\
15 & 72,900 & 3600 & 2.7225 & 4.6225 & 115.3476 \\
16 & 84,100 & 6400 & 3.5344 & 7.3984 & 165.8944 \\
$\sum_{i=1}^{m} X_{i j}^{2}$ & $2,331,900$ & 118,493 & 86.9175 & 123.0101 & 1357.8959 \\
$\sum_{i=1}^{m} X_{i j}^{2}$ & 1527.0560 & 344.2281 & 9.3230 & 11.0910 & 36.8496 \\
\hline & & & & \\
\hline
\end{tabular}

Table 7. Normalized weld properties.

\begin{tabular}{|c|c|c|c|c|c|}
\hline Sample No. & UTS, MPa & $\mathrm{CVN}, \mathrm{J}$ & $\mathrm{BP}, \mathrm{mm}$ & $\mathrm{BH}, \mathrm{mm}$ & $\mathrm{BW}, \mathrm{mm}$ \\
\hline 1 & 0.2750 & 0.3196 & 0.2188 & 0.2029 & 0.2936 \\
\hline 2 & 0.3274 & 0.2905 & 0.1201 & 0.2570 & 0.1395 \\
\hline 3 & 0.2488 & 0.2324 & 0.2767 & 0.2795 & 0.1959 \\
\hline 4 & 0.2096 & 0.2615 & 0.1105 & 0.2263 & 0.3099 \\
\hline 5 & 0.2685 & 0.1743 & 0.1555 & 0.3354 & 0.1452 \\
\hline 6 & 0.1441 & 0.2905 & 0.1126 & 0.1848 & 0.2396 \\
\hline 7 & 0.1834 & 0.1598 & 0.2156 & 0.1939 & 0.2909 \\
\hline 8 & 0.3340 & 0.3341 & 0.3754 & 0.3498 & 0.1221 \\
\hline 9 & 0.3143 & 0.2469 & 0.4054 & 0.2570 & 0.1859 \\
\hline 10 & 0.2096 & 0.1743 & 0.2306 & 0.1939 & 0.3039 \\
\hline 11 & 0.1637 & 0.2760 & 0.2038 & 0.2687 & 0.3365 \\
\hline 12 & 0.2030 & 0.2411 & 0.2596 & 0.1857 & 0.2660 \\
\hline 13 & 0.3405 & 0.2963 & 0.4097 & 0.2678 & 0.1134 \\
\hline 14 & 0.2816 & 0.2034 & 0.2413 & 0.2777 & 0.2258 \\
\hline 15 & 0.1768 & 0.1743 & 0.1770 & 0.1939 & 0.2915 \\
\hline 16 & 0.1899 & 0.2324 & 0.2017 & 0.2452 & 0.3495 \\
\hline Weight, $w_{j}$ & 0.20578 & 0.19674 & 0.19881 & 0.19220 & 0.20647 \\
\hline
\end{tabular}


The next step is to multiply each parameter value in Table 7, with their corresponding weights. This action leads to the creation of Table 8 .

This last step is to sum the parameters comprising of the higher the better (maximum) and the smaller the better (minimum) respectively. Table 9 is created and ranked therefrom.

\subsection{Discussion of Results}

\subsubsection{Categorization of Test Results}

This study investigates the utilization of standard deviation and multi-objective optimization on the basis of ratio analysis (MOORA) tools in the selection of appropriate gas metal arc welding process parameters.

Table 8. Clustered weld properties and bead geometry according to criteria.

\begin{tabular}{cccccc}
\hline \multirow{2}{*}{ Sample No. } & \multicolumn{3}{c}{ Maximum } & \multicolumn{2}{c}{ Minimum } \\
\cline { 2 - 6 } 1 & UTS, MPa & CVN, J & BP, mm & BH, mm & BW, mm \\
2 & 0.0566 & 0.0629 & 0.0435 & 0.0390 & 0.0606 \\
3 & 0.0674 & 0.0572 & 0.0239 & 0.0494 & 0.0288 \\
4 & 0.0512 & 0.0457 & 0.0550 & 0.0537 & 0.0404 \\
5 & 0.0431 & 0.0514 & 0.0220 & 0.0435 & 0.0640 \\
6 & 0.0553 & 0.0343 & 0.0309 & 0.0645 & 0.0300 \\
7 & 0.0297 & 0.0572 & 0.0224 & 0.0355 & 0.0495 \\
8 & 0.0377 & 0.0314 & 0.0429 & 0.0373 & 0.0601 \\
9 & 0.0687 & 0.0657 & 0.0746 & 0.0672 & 0.0252 \\
10 & 0.0647 & 0.0486 & 0.0806 & 0.0494 & 0.0384 \\
11 & 0.0431 & 0.0343 & 0.0459 & 0.0373 & 0.0627 \\
12 & 0.0337 & 0.0543 & 0.0405 & 0.0516 & 0.0695 \\
13 & 0.0418 & 0.0474 & 0.0516 & 0.0357 & 0.0549 \\
14 & 0.0701 & 0.0583 & 0.0815 & 0.0515 & 0.0234 \\
15 & 0.0580 & 0.0400 & 0.0480 & 0.0534 & 0.0466 \\
16 & 0.0364 & 0.0343 & 0.0352 & 0.0373 & 0.0602 \\
& 0.0391 & 0.0457 & 0.0401 & 0.0471 & 0.0722 \\
\hline
\end{tabular}

Table 9. Ranking step.

\begin{tabular}{ccccc}
\hline Sample No. & $\sum \max$ & $\sum \min$ & $\sum \max -\sum \min$ & Rank \\
\hline 1 & 0.1630 & 0.0996 & 0.0634 & 5 \\
2 & 0.1485 & 0.0782 & 0.0703 & 6 \\
3 & 0.1519 & 0.0941 & 0.0578 & 13 \\
4 & 0.1165 & 0.1075 & 0.0090 & 9 \\
5 & 0.1205 & 0.0945 & 0.0260 & 10 \\
6 & 0.1093 & 0.0850 & 0.0243 & 12 \\
7 & 0.1120 & 0.0974 & 0.0146 & 2 \\
8 & 0.2090 & 0.0924 & 0.1166 & 11 \\
9 & 0.1939 & 0.0878 & 0.1061 & 15 \\
10 & 0.1233 & 0.1000 & 0.0233 & 7 \\
11 & 0.1285 & 0.1211 & 0.0074 & 1 \\
12 & 0.1408 & 0.0906 & 0.0502 & 8 \\
13 & 0.2099 & 0.0749 & 0.1350 & 14 \\
14 & 0.1460 & 0.1000 & 0.0460 & 16 \\
15 & 0.1059 & 0.0975 & 0.0084 & Best \\
\hline
\end{tabular}


In the first instance, a layout matrix design is established as contained in Table 1. Table 2 contains the process parameters, which comprises of the current, voltage, electrode diameter, and welding speed. The process parameters are either in low level $(-)$ or high level $(+)$. The low and high levels of the process parameters in Table 2 are placed in their various locations in Table 1, where current, voltage, electrode diameter and welding speed are denoted, as A, B, C and $\mathrm{C}$ respectively in Table 1.

From Table 1, it can be seen that there is a sixteen process parameter layout design. Each process parameter welding operation was used to make five weldments. The UTS, and CVN of the weldments were determined by conducting the tensile test, as well as, the charpy V-Notch impact test. The height, width, and penetration of the bead geometry of these weldments were measured and determined. Table 3 classified these properties according to their quality values, which shows that the larger the UTS, CVN, and BP the better the quality of the weldment. Whereas, the smaller the BH and BW the better the quality of the weldment.

This is because, UTS defines the strength of the weldment. Therefore, the greater the strength of the weldment, the more the weldment possesses the capacity to carry loads. This quality actually extends the service life of the weldment. The CVN measures the energy required to absorb impact loads. The higher the CVN value, the greater the chances of the weldments to absorb any applied impact load. This on the one hand tends to increase the service life of the weldment. The weld bead penetration is an important factor considered in assessing the quality of weldments. The higher the weld penetration, the lower the weld undercuts, and the higher the weld joint reinforcements. This however increases the strength and quality of the weldment.

Table 4 shows the sixteen standard deviations, determined for each of the mechanical properties, whereas, Table 5 shows the overall standard deviations and the corresponding weights assigned to each mechanical property. Tables 6-9 show the MOORA application process for determining the optimum welding process parameters.

\subsubsection{Result Analysis}

The UTS considered in this study is within the range of $220 \mathrm{MPa}$ and $520 \mathrm{MPa}$. Appling MOORA the selected process parameters thereof produced a weldment with a UTS of $520 \mathrm{MPa}$. The CVN considered in this study is in the range of $55 \mathrm{~J}$ and $115 \mathrm{~J}$. By Appling the MOORA a CVN of $100 \mathrm{~J}$ was obtained. This indicates that when the CVN value is above the threshold value of $100 \mathrm{~J}$. This may negatively affect on the long term the service life of the weldment.

The BP considered in this study is within the range of $1.03 \mathrm{~mm}$ and $3.8 \mathrm{~mm}$. By applying the MOORA technique, BP was found to be $3.83 \mathrm{~mm}$. This indicates that the more the gaps between the weld joints are covered by the molten weld metal, the better, because the strength is increased, porosity is reduced to the barest minimum or eliminated, and the weld joints are held together to an acceptable level. This study shows that the joint gap of weldment 13 was fully covered by the molten weld metal.

On the other hand, the second category shows that the smaller the bead height and bead width the better the quality of the weldment. This corresponds with actual welding practice. The smaller the $\mathrm{BH}$ and $\mathrm{BW}$ are, the better the quality of the weldment will be. The range of $\mathrm{BH}$ considered in this study is $2.05 \mathrm{~mm}$ and $3.88 \mathrm{~mm}$. By applying the MOORA method, the $\mathrm{BH}$ obtained was $2.97 \mathrm{~mm}$. This indicates that $\mathrm{BH}$ of $2.05 \mathrm{~mm}$ was too small to be considered and a BH below $2.97 \mathrm{~mm}$ may not have enough weld metal to sustain the strength possessed by the weldment when loads are applied. Therefore, for this study, BH with a value of $2.97 \mathrm{~mm}$ is considered the threshold value when using the optimum process parameters. The BW considered in this study is within the range of $4.18 \mathrm{~mm}$ and $12.88 \mathrm{~mm}$. By applying the MOORA method, BW of $4.18 \mathrm{~mm}$ was obtained. This indicates that BW values above $4.18 \mathrm{~mm}$ may contain too much weld metal. Too much weld metal adds to the weight of the weldment and this may not be good for the overall structure of the material.

For this study, weldment 13 , is found to possess the best mechanical property. From Table 1 and Table 2 , the process parameters for weldment 13 correspond to a welding current of $350 \mathrm{~A}$, a welding voltage of $22 \mathrm{~V}$, an electrode diameter of $3.2 \mathrm{~mm}$ and welding speed of $100 \mathrm{~mm} / \mathrm{s}$. The mechanical properties produced by the weldment made by these process parameters are UTS of $520 \mathrm{MPa}, \mathrm{CVN}$ of $100 \mathrm{~J}$, BP of $3.8 \mathrm{~mm}, \mathrm{BH}$ of 2.97 $\mathrm{mm}$ and $\mathrm{BW}$ of $4.18 \mathrm{~mm}$.

The results from this study were compared with similar work found in literature. Such as Gunaraj and Murugan [20] who predicted and optimized the weld bead volume for submerged arc process and obtained bead penetration of between the range of $3.04 \mathrm{~mm}$ and $3.80 \mathrm{~mm}$, and bead width was in the range of $7.9 \mathrm{~mm}$ and 9.1 $\mathrm{mm}$. From this study, the BP matches that obtained by Gunaraj and Murugan [20] and also the BW obtained in 


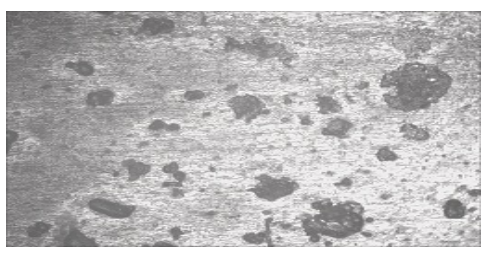

Figure 5. Microstructure of weldment from optimized process parameters.

this study is better than the one determined by Gunaraj and Murugan [20].

Figure 5 shows the microstructure of the optimized weldment. From the microstructural view it can be seen that the black and white colours are heterogeneously prominent. The white grains are ferrite, while the black ones are the pearlite. However, pearlite contains ferrite and cementite. Cementite is considered to be very hard and dense. From Figure 5, it can be seen that obviously pearlite is more in proportion than ferrite. As a result of this, the strength, that is the UTS of the optimized weldment is expected to be high and the weldment ductile as the ferrite is considerably high. Since it is observed that the optimized process parameters gave a good level of weld metal penetration, the fusion between the parent material and the weld metal would also be high with very good machinability because of its ductility. This analysis reveals that the optimized weldment is of very good quality.

\section{Conclusions}

Mild steel plates were joined by applying specific process parameters to carry out the welding operation. The weld metals were machined into various test specimens. Mechanical properties, UTS, and CVN were determined using the test specimens. The mechanical properties were found within the category. The larger the test result was, the better the quality of the weldment would be, whereas the individual weldment was bisected and BP, BH and BW were measured.

BP falls into the larger the test result, the better the quality of the weldment whereas, BH and BW fall into the smaller the test results, the better the quality of the weldment or bead geometry. The MOORA technique was applied to optimally select the welding process parameters that produced the weldment with the best properties. However, standard deviation was used to determine the weights allocated to each value of the mechanical property utilized in the course of running the MOORA process.

This study summarily covers the application of MOORA method in the selection of optimized welding process parameters for welding mild steel plates using the gas metal arc welding techniques. This multi-objective optimization tool utilizes a ranking method for the process parameters selection process.

From the results obtained, it can be found that the selected optimized process parameters are within the range of optimized process parameters obtained in literature. It is hereby concluded that MOORA method has successfully optimized the process parameters considered in this study and that these optimized process parameters are compared well with those obtained by other investigators who apply other known optimization models. The microstructure of the weldment produced by the optimized process parameters was also investigated to confirm the quality of the weldment. The analysis of the microstructure reveals that the weldment produced by the optimized process parameters is of excellent weld quality.

\section{References}

[1] Görener, A., Dinçer, H. and Hacıoğlu, Ü. (2013) Application of Multi-Objective Optimization on the Basis of Ratio Analysis (MOORA) Method for Bank Branch Location Selection. International Journal of Finance \& Banking Studies, 2, 41-52.

[2] Brauers, W.K. (2003) Optimization Methods for a Stakeholder Society, a Revolution in Economic Thinking by Multi-Objective Optimization, Series: Nonconvex Optimization and Its Applications, 73. Kluwer Academic Publishers, Boston, 342.

[3] Brauers, W.K.M., Zavadskas, E.K., Turskis, Z. and Vilutiene, T. (2008) Multi-Objective Contractors's Ranking by Applying the MOORA Method. Journal of Business Economics and Management, 9, 245-255. http://dx.doi.org/10.3846/1611-1699.2008.9.245-255

[4] Brauers, W.K.M., Ginevičius, R. and Podvezko, V. (2010) Regional Development in Lithuania Considering Multiple 
Objectives by the MOORA Method. Technological and Economic Development of Economy, 16, 613-640. http://dx.doi.org/10.3846/tede.2010.38

[5] Gadakh, V.S., Shinde, V.B. and Khemnar, N.S. (2013) Optimization of Welding Process Parameters Using MOORA Method. The International Journal of Advanced Manufacturing Technology, 69, 2031-2039. http://dx.doi.org/10.1007/s00170-013-5188-2

[6] Hwang, C.L. and Yoon, K.P. (1995) Multiple Attribute Decision Making and Introduction. Sage Publication, London, 2.

[7] Mandel, U.K. and Sarkar, B. (2012) Selection of Best Intelligent Manufacturing System (IMS) Under Fuzzy MOORA Conflicting MCDM Environment. International Journal of Emerging Technology and Advanced Engineering, 2, 301310 .

[8] Stanujkic, D. Dordevic, B. and Dordevic, M. (2013) Comparative Analysis of Some Prominent MCDM Method: A case of Ranking Serbian Banks. Serbian Journal of Management, 8, 213-241. http://dx.doi.org/10.5937/sjm8-3774

[9] Brauers, W.K.M. and Zavadskas E.K. (2006) The MOORA Method and Its Applications to Privatization in a Transition Economy. Control and Cybernetics, 35, 445-469.

[10] Chakraborty, S. (2010) Application of the MOORA Method for Decision Making in Manufacturing Environment. International Journal of Advanced Manufacturing Technology, 54, 1155-1166. http://dx.doi.org/10.1007/s00170-010-2972-0

[11] Karande, P. and Chakraborty, S. (2012) Application of Multi-Objective Optimization on the Basis of Ratio Analysis (MOORA) Method for Materials Selection. Materials and Design, 37, 317-324. http://dx.doi.org/10.1016/j.matdes.2012.01.013

[12] Chaturved, V. and Sharma, A.K. (2014) Parametric Optimization of CNC Wire Cut EDM for OHNS Steel Using MOORA Methodology. Proceedings of the 10th IRF International Conference, Bengaluru, 4 October 2014, 79-84.

[13] Brauers, W.K.M. and Zavadskas, E.K. (2010) Project Management by Multimoora as an Instrument for Transition Economics. Technological and Economic Development of Economy, 16, 5-24. http://dx.doi.org/10.3846/tede.2010.01

[14] Ozcelik, G., Aydogan, E.K. and Gencer, C. (2014) A Hybrid Moora-Fuzzy Algorithm for Special Education and Rehabilitation Centre Selection. Journal of Military and Information Science, 2, 53-62. http://dx.doi.org/10.17858/jmisci.53708

[15] Farzamnia, F. and Babolghani, M.B. (2014) Group Decision Making Process for Supplier Selection Using Multimoora Technique under Fuzzy Environment. Kuwait Chapter of Arabian Journal of Business and Management Review, 3, 203-218.

[16] Prasad, K.S., Rao, C.S. and Rao, D.N. (2011) Optimizing Pulsed Current Micro Plasma Arc Welding Parameters to Maximize Ultimate Tensile Strength of Inconel 625 Nickel Alloy Using Response Surface Method. International Journal of Engineering Science and Technology, 3, 226-236.

[17] Kim, D., Kang, M. and Rhee, S. (2005) Determination of Optimal Welding Conditions with a Controlled Random Search Procedure. Welding Journal, 84, 125-130.

[18] El-Santawy, M.F. and Ahmed, A.N. (2012) Analysis of Project Selection by Using SDV-MOORA Approach. Life Science Journal, 9, 129-131.

[19] Kalibatas, D. and Turskis, Z. (2008) Multicriteria Evaluation of Inner Climate by Using MOORA Method. Information Technology and Control, 37, 79-83.

[20] Gunaraj, V. and Murugan, N. (2000) Prediction and Optimization of Weld Bead Volume for the Submerged Arc Process-Part 2. Welding Journal, 79, 331s-338s. 